\title{
Bioprospecting Through Cloning of Whole Natural Product Biosynthetic Gene Clusters
}

\author{
Zhenquan Lin', Jens Nielsen ${ }^{1,2,3,4}$ and Zihe Liu ${ }^{1 *}$ \\ ${ }^{1}$ Beijing Advanced Innovation Center for Soft Matter Science and Engineering, College of Life Science and Technology, \\ Beijing University of Chemical Technology, Beijing, China, ${ }^{2}$ Department of Biology and Biological Engineering, Chalmers \\ University of Technology, Gothenburg, Sweden, ${ }^{3}$ Novo Nordisk Foundation Center for Biosustainability, Technical University \\ of Denmark, Lyngby, Denmark, ${ }^{4}$ Biolnnovation Institute, Copenhagen, Denmark
}

OPEN ACCESS

Edited by: Jiazhang Lian,

Zhejiang University, China

Reviewed by:

Yinhua Lu,

Shanghai Normal University, China

Yajie Wang,

University of Illinois

at Urbana-Champaign, United States

${ }^{*}$ Correspondence:

Zihe Liu

zihe@mail.buct.edu.cn

Specialty section:

This article was submitted to

Synthetic Biology,

a section of the journal

Frontiers in Bioengineering and

Biotechnology

Received: 25 March 2020

Accepted: 04 May 2020

Published: 05 June 2020

Citation:

Lin Z, Nielsen J and Liu Z (2020) Bioprospecting Through Cloning of Whole Natural Product Biosynthetic

Gene Clusters.

Front. Bioeng. Biotechnol. 8:526.

doi: 10.3389/fbioe.2020.00526
Since the discovery of penicillin, natural products and their derivatives have been a valuable resource for drug discovery. With recent development of genome mining approaches in the post-genome era, a great number of natural product biosynthetic gene clusters (BGCs) have been identified and these can potentially be exploited for the discovery of novel natural products that can find application as pharmaceuticals. Since many BGCs are silent or do not express in native hosts under laboratory conditions, heterologous expression of BGCs in genetically tractable hosts becomes an attractive route to activate these BGCs to discover the corresponding products. Here, we highlight recent achievements in cloning and discovery of natural product biosynthetic pathways via intact BGC capturing, and discuss the prospects of high-throughput and multiplexed cloning of rational-designed gene clusters in the future.

Keywords: natural product, biosynthetic gene cluster, heterologous expression, sequence-independent cloning, direct cloning

\section{INTRODUCTION}

Natural products produced by plant, bacteria, and fungi have served as a crucial source of pharmaceuticals, therapeutic agents and industrially useful compounds, such as antibiotic, antitumor, and anti-infective drugs (Nielsen, 2019). Since the discovery of penicillin in the early 1940s, the identification and bioprospection of natural product biosynthetic gene clusters (BGCs) has attracted much attention (Mullis et al., 2019). With the development of sequencing technologies, the costs of genome sequencing has been reduced, and hereby metagenomics has emerged as a strategic approach to explore unculturable microbes through the sequencing and analysis of environmental DNA. Hereby massive DNA sequence information has become accessible. Moreover, many bioinformatic tools have been developed to uncover putative BGCs, such as antiSMASH 5.0 (Blin et al., 2019), BiG-SCAPE (Navarro-Muñoz et al., 2019), PRISM 3 (Skinnider et al., 2017), MIBiG 2.0 (Kautsar et al., 2019), RODEO (Tietz et al., 2017), and genomescale metabolic models (Nielsen and Nielsen, 2017). However, there are many technical challenges to translate these putative BGCs into specialized chemicals, resulting in a huge gap in the natural product discover pipeline (Dejong et al., 2016).

Advances in genetics, molecular biology and synthetic biology have been successfully used for natural product discovery (Zhang J. J. et al., 2019; Zhao et al., 2019). It has been estimated that more than $99 \%$ of environmental microbes are unculturable under the defined conditions using routine techniques and hard to study using classical experimental approaches (Daniel, 2005). Moreover, a large number of BGCs are not or weakly expressed in native hosts 
under laboratory conditions, known as 'silent' or 'cryptic' gene clusters. Thus, besides the traditional screening and characterization methods, such as phenotype screening, insertional mutagenesis, co-culture and elicitor screening (Cacho et al., 2015; Tomm et al., 2019; Zhang X. et al., 2019), cloning and refactoring the putative BGCs in well-defined hosts become attractive approaches for natural product discovery, achieving functional expression of uncharacterized potentially-valuable natural product biosynthetic pathways (Cook and Pfleger, 2019; Xu et al., 2020). While E. coli, Streptomyces, yeast and Aspergillus are often used for heterogeneous expression of BGCs, their applications are still limited by the incompatibility of different transcript regulatory systems and codon preferences among organisms, lack of post-translational protein modifications, insufficient supplies of precursors and co-factors, toxicity of intermediates or final products, and poor assembly of natural products with novel structure (Luo et al., 2016; Nielsen, 2019; Pham et al., 2019). Unlike prokaryotic gene clusters, heterogeneous expression for eukaryotic gene clusters or individual genes introduces additional challenges for heterologous expression, such as intron splicing, insertion of promoters and terminators in upstream and downstream of each coding region, etc. (Alberti et al., 2017; Harvey et al., 2018; Qiao et al., 2019). Many alternative methods have been developed and comprehensively reviewed elsewhere (Baker et al., 2018; Xiong et al., 2019; Deng et al., 2020).

Over the past decade, many approaches have been developed to clone intact BGCs for heterologous expression. However, cloning long genome segments of large gene clusters (range from 20 to $\sim 200 \mathrm{~kb}$ ) remains challenging (Fayed et al., 2015). Thus, it's necessary to develop appropriate vector systems and methods for cloning large-size gene clusters and transfer these genetic segments between different hosts (Liao et al., 2019). In this review, we will focus on recent developments of cloning intact gene clusters from complex genome sequence for natural products discovery, including sequence-independent methods and direct cloning methods, and prospect on high-throughput multiplexed cloning of BGCs.

\section{SEQUENCE-INDEPENDENT METHODS FOR HETEROGENEOUS EXPRESSION OF BGCs}

Sequence-independent method constructs expression libraries on sheared genomes from a mixed population (e.g., environmental DNA) or a pure culture, and screens for natural products. Key technologies in sequence-independent methods include high-quality high-molecular-weight DNAs isolation, DNA fragmentation and library construction. This method is particularly useful for scenarios when the genomic information of native hosts is under-characterized. Sequence-independent methods have the advantage to prospect the entire genetic materials, and is possible to cover all the BGCs in the sample and discover novel structural natural products (Zhang J. J. et al., 2019). The approach does, however, require highly efficient screening assays as the library will have a very low fraction of positives. Many groups have successfully used sequence-independent library cloning based on different library construction strategies [e.g., cosmids, fosmids, bacterial artificial chromosomes (BACs), phage artificial chromosomes (PACs)] for natural product discovery (Table 1) (Deng et al., 2017; Nara et al., 2017).

\section{Isolation of High-Quality High-Molecular-Weight DNAs}

Biosynthetic gene clusters are often 10s of kilobase and even over $100 \mathrm{~kb}$. Thus, methods for preparing high-quality and highmolecular-weight DNAs are critical for successful cloning of intact BGCs. Zhang et al. (2010) reported a method of extracting high-molecular-weight DNAs from a variety of biological materials using CTAB (cetyl trimethyl ammonium bromide) extraction buffer for extraction, followed by phenolchloroform extraction and/or ethanol precipitation. However, this method often causes long DNA molecules shearing, and is used for extracting genomic DNAs up to $\sim 10 \mathrm{~kb}$. To prepare megabasesize genomic DNA, cellulase and pectinase were firstly used to hydrolyze the cell wall before isolating DNAs from organisms having a cell walls (Zhang et al., 2012). Unlike conventional genomic DNA isolation methods, the protoplast, cells, or the nuclei are embedded in low-melting-point agarose gel matrix to protect large DNA fragments from mechanical shearing during the isolation step (Zhang et al., 2012). Alternatively, for rapid extraction of high-molecular-weight genomic DNA (range from $\sim 20$ to $\sim 130 \mathrm{~kb}$ ) from bacteria, plants, and animals, Mayjonade et al. (2016) developed a method that grounds the cell into a fine powder in liquid nitrogen, lyses the cell with SDS-base buffer and finally uses carboxylated magnetic beads to purify the DNA. For more information on the topic of isolating high-quality DNAs, please refer to recent reviews elsewhere (Mohamad Roslan et al., 2017; Green and Sambrook, 2018). Commercial kits for extracting high-molecular-weight DNA are also available (e.g., QIAGEN, Macherey Nagel). A detailed comparison of each method can be found in Supplementary Table S1.

\section{DNA Fragmentation}

Methods available for DNA fragmentation in library construction include enzymatic digestion, sonication, and hydrodynamic shearing (Ignatov et al., 2019). Enzymatic digestion, such as using site-directed restriction enzyme Sau3AI to partial digest purified DNA (Clos and Zander-Dinse, 2019), sonication, such as using ultrasound to generate $>120 \mathrm{~kb}$ fragments (Bhushan et al., 2011), and hydrodynamic shearing, such as repeatedly passing DNA through a syringe needle (Liu C. et al., 2016), have been widely used for constructions of large-fragment libraries. Compared with enzymatic shearing, sonication and hydrodynamic shearing, which are mechanical fragmentation methods, are more random and enable better control of the size distribution ( $\mathrm{Li}$ et al., 2017). After fragmentation, DNA samples can be analyzed by fragment analyzer or horizontal agarose gel electrophoresis to test the extent of the yield fragments. Desired size of fragmented DNAs can 
TABLE 1 | Different strategies for intact natural product BGCs cloning.

\begin{tabular}{|c|c|c|c|c|c|c|}
\hline Class & Strategies & Principles & Capacity & Advantages & Disadvantages & BGCs \\
\hline \multirow[t]{3}{*}{$\begin{array}{l}\text { Sequence- } \\
\text { independent } \\
\text { libraries cloning }\end{array}$} & $\begin{array}{l}\text { Cosmid/ } \\
\text { fosmid } \\
\text { libraries }\end{array}$ & $\begin{array}{l}\text { - Fragmentation, gel-fractionated, } \\
\text { ligation and phage packaging }\end{array}$ & $<50 \mathrm{~kb}$ & $\begin{array}{l}\text { - Not requiring genome sequence data; } \\
\text { - Capable of generating natural product } \\
\text { with novel structure; } \\
\text { - Capable of covering the complete } \\
\text { genetic material; } \\
\text { - Suitable for cloning environmental } \\
\text { DNA. }\end{array}$ & $\begin{array}{l}\text { - Untargeted; } \\
\text { - Laborious and time consuming; } \\
\text { - Packaging; } \\
\text { - Large BGCs maybe spanned into } \\
\text { separatebd clones. }\end{array}$ & $\begin{array}{l}\text { Omnipeptin (Libis et al., 2019) } \\
\text { Anisomycin (Zheng et al., 2017) } \\
\text { Ashimides (Shi et al., 2019) } \\
\text { Frigocyclinone (Mo et al., 2019) } \\
\text { Locillomycins (Luo et al., 2019) }\end{array}$ \\
\hline & $\begin{array}{l}\text { PAC/BAC } \\
\text { libraries }\end{array}$ & $\begin{array}{l}\text { - Fragmentation, gel-fractionated, and } \\
\text { ligation }\end{array}$ & $<300 \mathrm{~kb}$ & $\begin{array}{l}\text { - Not requiring genome sequence data; } \\
\text { - Capable of generating natural product } \\
\text { with novel structure; } \\
\text { - Capable of covering the complete } \\
\text { genetic material. }\end{array}$ & $\begin{array}{l}\text { - Untargeted; } \\
\text { - Laborious and time consuming; } \\
\text { - Technically challenging for large } \\
\text { fragment cloning and DNA extraction. }\end{array}$ & $\begin{array}{l}\text { Atratumycin (Yang et al., 2019) } \\
\text { Neoabyssomicin/abyssomicin (Tu } \\
\text { et al., 2018) } \\
\text { Avermectins (Deng et al., 2017) } \\
\text { Murayaquinone (Peng et al., 2018) }\end{array}$ \\
\hline & $\begin{array}{l}\text { FAC } \\
\text { libraries }\end{array}$ & $\begin{array}{l}\text { - Random fragmentation, adaptors } \\
\text { ligation, gel-fractionated and ligation }\end{array}$ & 10-200 kb & $\begin{array}{l}\text { - Unbiased library; } \\
\text { - Not requiring genome sequence data; } \\
\text { - Capable of generating natural product } \\
\text { with novel structure; } \\
\text { - Suitable for fungal BGCs cloning. }\end{array}$ & $\begin{array}{l}\text { - Untargeted; } \\
\text { - Laborious and time consuming. }\end{array}$ & $\begin{array}{l}\text { Sesterterpenoid (Clevenger et al., } \\
\text { 2017) } \\
\text { Benzomalvin A/D (Clevenger et al., } \\
\text { 2018) } \\
\text { Diketomorpholines (Robey et al., } \\
\text { 2018) }\end{array}$ \\
\hline \multirow[t]{5}{*}{ Direct cloning } & TAR & $\begin{array}{l}\text { - In vivo homologous recombination of } \\
\text { Saccharomyces cerevisiae }\end{array}$ & $<100 \mathrm{~kb}$ & $\begin{array}{l}\text { - Cas9-facilitated high efficiency } \\
\text { cloning; } \\
\text { - Suitable for cloning large genomic } \\
\text { regions. }\end{array}$ & $\begin{array}{l}\text { - Technically challenging to use yeast } \\
\text { spheroplasts for highly transformation } \\
\text { efficient; } \\
\text { - Some false positives; } \\
\text { - Requires careful preparation and/or } \\
\text { manipulation of gDNA. }\end{array}$ & $\begin{array}{l}\text { Plipastatin (Hu et al., 2018) } \\
\text { Scleric acid (Alberti et al., 2019) } \\
\text { Brasiliquinones (Herisse et al., 2019). }\end{array}$ \\
\hline & LLHR & $\begin{array}{l}\text { - RecET-mediated linear-plus-linear } \\
\text { homologous recombination in E. coli }\end{array}$ & $<\sim 52 \mathrm{~kb}$ & $\begin{array}{l}\text { - Technically easier; } \\
\text { - Suitable for cloning small- and mid- } \\
\text { BGCs; } \\
\text { - Simply for using short recombination } \\
\text { homologous arms. }\end{array}$ & $\begin{array}{l}\text { - False positive; } \\
\text { - Difficult to clone large-size BGCs; } \\
\text { - Require highly specialized capturing } \\
\text { vectors; } \\
\text { - Multi-rounds selection. }\end{array}$ & $\begin{array}{l}\text { Luminmide A/B (Fu et al., 2012) } \\
\text { Bacillomycin (Liu Q. et al., 2016) } \\
\text { Streptoketides (Qian et al., 2020) }\end{array}$ \\
\hline & EXOCET & $\begin{array}{l}\text { - CRISPR/Cas9 digestion, T4 } \\
\text { polymerase for in vitro annealing and } \\
\text { RecET mediated homologous } \\
\text { recombination }\end{array}$ & $<\sim 102 \mathrm{~kb}$ & $\begin{array}{l}\text { - Technically easier; } \\
\text { - Simply for using short recombination } \\
\text { homologous arms. }\end{array}$ & $\begin{array}{l}\text { - Low efficiency for clone large-size } \\
\text { BGCs; } \\
\text { - Require pathway specialized vectors; } \\
\text { - False positive. }\end{array}$ & $\begin{array}{l}\text { Salinomycin (Wang et al., 2018) } \\
\text { Spinosad (Song et al., 2019) }\end{array}$ \\
\hline & CATCH & $\begin{array}{l}\text { - Cas9-assisted site-specific cleavage } \\
\text { and Gibson assembly }\end{array}$ & $<\sim 150 \mathrm{~kb}$ & $\begin{array}{l}\text { - Suitable for cloning large genomic } \\
\text { regions. }\end{array}$ & $\begin{array}{l}\text { - Require carefully prepare the target } \\
\text { DNA in gel. }\end{array}$ & $\begin{array}{l}\text { Bacillaene (Jiang et al., 2015) } \\
\text { Mutanocyclin/SNC1-465 (Hao et al., } \\
\text { 2019) }\end{array}$ \\
\hline & $\mathrm{DiPaC}$ & $\begin{array}{l}\text { - Q5 hi-fidelity PCR amplication and } \\
\text { Gibson assembly }\end{array}$ & $\begin{array}{l}<22 \mathrm{~kb} \\
\text { per round }\end{array}$ & $\begin{array}{l}\text { - Technically easier; } \\
\text { - Extremely efficient for cloning small- to } \\
\text { mid-size BGCs. }\end{array}$ & $\begin{array}{l}\text { - Introduction of new mutations during } \\
\text { PCR; } \\
\text { - Impractical for large BGCs. }\end{array}$ & $\begin{array}{l}\text { Phenazine fontizine A5 (Greunke } \\
\text { et al., 2018) } \\
\text { Sodorifen (Duell et al., 2019) } \\
\text { Hapalosin (D’Agostino et al., 2018) }\end{array}$ \\
\hline
\end{tabular}




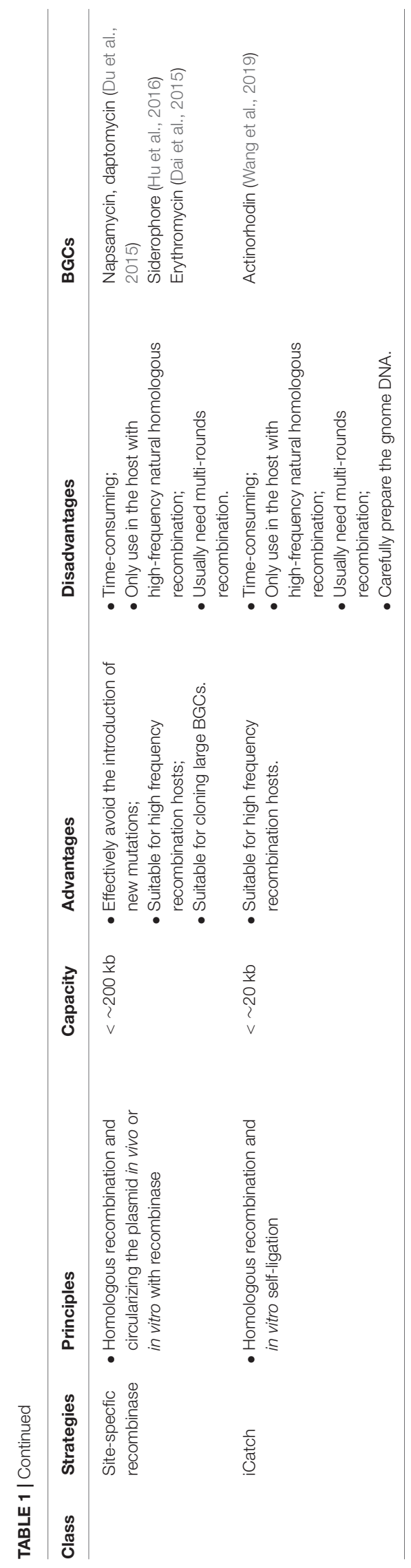

be separated and extracted using multi-rounds of pulsed field gel electrophoresis (PFGE) with different ramped pulse times (Clos and Zander-Dinse, 2019). Compared to mechanical fragmentation methods, the unevenly distributed restriction sites in the genome may cause inherently biased and incomplete library with enzyme methods.

\section{Cloning Strategies}

After fragmentation and purification, the desired size of fragmented DNAs can be separated by multi-rounds PFGE. The size-selected fragments were end-repaired and ligated to the digested and dephosphorylated vector, such as cosmid, fosmid, BAC, or PAC (Table 1) (Liu et al., 2018; Tu et al., 2018; Clos and Zander-Dinse, 2019). Total ligation products can be transformed into E. coli or packaged into a phage for infecting bacteria. The insert size of cosmid/fosmid libraries usually is limited to $\sim 50 \mathrm{~kb}$, thus, large gene clusters are often split into multiple fragments and reassemble into the whole cluster (Wolpert et al., 2008). Alternatively, PACs can clone inserts ranging in size from 60 to $150 \mathrm{~kb}$, while BACs have a capacity to accommodate and propagate DNA fragments with an average insert size $\sim 150 \mathrm{~kb}$ (Bilyk et al., 2016). Several of these technologies have been turned into products, commercialized by a variety of companies such as Agilent, Bio S\&T, and Epicentre Biotechnologies. For unbiased fungal artificial chromosome (FAC) library construction, fragmented DNAs was end-repaired and ligated with BstXI adaptors and after for separating desired sizes DNA by PFGE (Bok et al., 2015). Purified large DNA fragments were ligated into the BstXI-digested shuttle vectorFAC. The average inserts size of FAC libraries was about $150 \mathrm{~kb}$, which can cover most fungal BGCs.

\section{Successful Applications}

The above-mentioned DNA assembly methods were developed in the past decades, and there are already many successful applications (Table 1). For example, Libis et al. (2019) have screened a 10 million cosmid library from soil metagenomic DNA samples using Co-occurrence Network Analysis of Targeted Sequences (CONKAT-seq), and identified omnipeptin. Moreover, Bok et al. (2015) have constructed a novel AspergillusE. coli shuttle FAC expression vector coupling a BAC vector backbone with an autonomous fungal replicating element AMA1 from Aspergillus nidulans. Clevenger et al. (2017) had then optimized the FAC-cloning method, and developed fungal artificial chromosomes with metabolomic scoring (FAC-MS) platform for the discovery of fungal specialized metabolites. Utilizing this approach, researchers have screened fragmented genome DNA containing uncharacterized fungal BGCs from A. terreus, A. aculeatus, and A. wentii, and discovered 17 compounds including 15 unreported compounds (Clevenger et al., 2017), including benzomalvin A/D (Clevenger et al., 2018), diketomorpholines (Robey et al., 2018).

In summary, sequence-independent library cloning can generate libraries for both un-sequenced and sequenced DNAs, with each clone harboring 10 to $\sim 200 \mathrm{~kb}$ inserts, promoting the natural product discovery. However, sequence-independent library cloning is usually laborious and time consuming. For 
example, to reliably cover the whole genome, researchers usually need to generate 10-20 folds genome coverage to obtain the clones harboring BGCs (Bok et al., 2015). This will require optimization of the whole cloning process, for example, the genome extraction should not result in too much genomic fragmentation, the assembly including the transformation step should be highly efficient to generate the required library size, etc. Moreover, desired BGCs may be split into different clones, especially when using cosmid/fosmid libraries to screen and identify large gene clusters.

\section{DIRECT CLONING METHODS FOR HETEROGENEOUS EXPRESSION OF BGCs}

Direct cloning methods rely on precise bioinformatics to predict BGCs with targeted functions and use specialized cloning method to capture target sequence for expression and/or identification of secondary metabolites. The development of sequencing technologies has resulted in a dramatic reduction of sequencing cost, thus the genome or metagenome information can be easily generated. Meanwhile, several bioinformatic tools have been developed and successfully applied to identify BGCs with potential functions, including PRISM 3 (Skinnider et al., 2017), BiG-SCAPE (Navarro-Muñoz et al., 2019), and antiSMASH (Blin et al., 2019). Direct cloning methods aim to bypass the conventional library generation and screening process and directly isolate gene clusters of interest. Several groups have developed different approaches for direct capture of the BGCs (Figure 1 and Table 1) (Hu et al., 2018; Alberti et al., 2019).

\section{DNA Isolation and Fragmentation}

Methods of DNA isolation and fragmentation for direct cloning are similar with methods used in sequence independent strategies. For DNA fragmentation, physical methods maybe caused target BGCs shearing into fragments. Moreover, the target BGCs are usually too large to find appropriate restriction enzymes that are capable to digest flank homologous regions without also digesting internal targets. To simplify the capture of BGCs, Greunke et al. (2018) developed the direct pathway cloning $(\mathrm{DiPaC})$ method that utilizes long-amplicon PCR to generate target region and Gibson assembly to construct expression plasmids in vitro, as shown in Figure 1B. This method is capable of direct cloning small- to mid-sized BGCs (up to $<22 \mathrm{~kb}$ per round), resulting in discovery of phenazine fontizine A5 (Greunke et al., 2018), sodorifen (Duell et al., 2019), and heterologous production of anabaenopeptin and erythromycin (Greunke et al., 2018).

The development of advancing genome editing tools, such as clustered regularly interspaced short palindromic repeat-CRISPR-associated protein (CRISPR-Cas) system, has substantially accelerated the process of direct cloning and made it possible to isolate the exact sequence of target BGCs in vitro (Lee et al., 2015; Wang et al., 2018; Tao et al., 2019). For example, Jiang et al. (2015) developed Cas9-Assisted Targeting of Chromosome (CATCH) using CRISPR/Cas9 to generate double strand breaks at both ends of target BGCs in vitro, and cloned a 78-kb bacillaene gene cluster from Bacillus subtilis using Gibson assembly. The concentration of extracted BGCs from target genome or metagenome without enrichment may be too low to yield efficient cloning, and spheroplasts can be used to increase transformation efficiency in transformation-associated recombination (TAR) (Kouprina et al., 2020).

\section{Cloning Strategies}

The development of synthetic biology tools have enhanced cloning of intact BGCs in heterologous hosts (Table 1). Some of these methods are based on exonucleases to "chew back" one of the strands of double-stranded DNAs, thereby exposing complementary single-stranded DNA sequences that can anneal to each other in vitro (Figures 1A,B), such as Gibson isothermal assembly (Jiang et al., 2015; Greunke et al., 2018), sequenceand ligation-independent cloning (SLIC) (D'Agostino et al., 2018). Blunt-end ligation have also been emplyed to ligate the CRISPR/Cas9 digested product into a universal vector for $\lambda$ packaging into phage and transfecting into E. coli (Tao et al., 2019) (Figure 1A).

This "chew-back and repair" mechanism has also been applied to clone intact BGCs leveraging on in vivo homologous recombination (Figure $\mathbf{1 C}$ and Table 1). Several hosts have been widely used for cloning purpose, such as the TAR method in Saccharomyces cerevisiae (Kouprina and Larionov, 2019), linear-linear homologous recombination (LLHR) or linear plus circular homologous recombination (LCHR) in E. coli (Fu et al., 2012), and exonuclease combined with RecET recombination (ExoCET) (Wang et al., 2018). In these methods, partially digested or randomly sheared DNA was co-transformed into the recombinant host with linearized and pathway-specific vectors containing homology arms that flank the upstream and downstream of the target BGCs. Also, ExoCET can be used to promote homologous recombinations between a linear DNA molecule and a circular plasmid (Fu et al., 2012).

Another type of approach employs site-direct recombination to clone intact BGCs by first integrating specific-vector with the integrase recognition sites in the native host, then the targeted BGCs together with the integrated vector are captured and circularized for heterologous expression (Figures 1D,E and Table 1). This approach requires the native host to have high efficiency of homologous recombination. For example, Dai et al. (2015) intergrated plasmid pEry-up and pEry-down with the BT1 integrase recognition sites BattP and BattB via single- or double- crossover at both ends of erythromycin BGC, after which genome DNA was carefully isolated and treated with the BT1 integrase to circularize at att recombination sequences as a plasmid via in vitro site-specific recombination. Similarily, iCatch intergrates homing endonucleases I-SceI and PI-PspI recognition sites flanking the region of interest, after which the genome is isolated and digested with I-SceI or PI-PspI and then self-ligated to clone the target BGC in vitro (Wang et al., 2019). Moreover, several groups have developed methods that express recombinases to extract DNA fragments between two integrase recognition sites and circularize the plasmid in vivo (Figure 1D), such as phage $\phi B T 1$ integrase-mediated site-specific 
A

Restriction enzyme digested/CRISPRCas9 treated gDNA

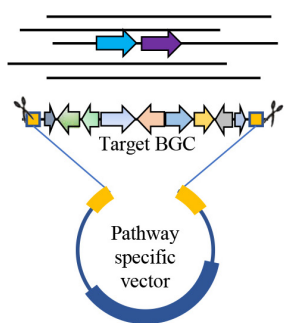

Ligation/Gibson assembly in vitro, Transform/transfect into E. coli

$\checkmark$

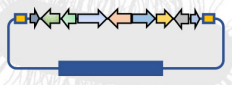

B

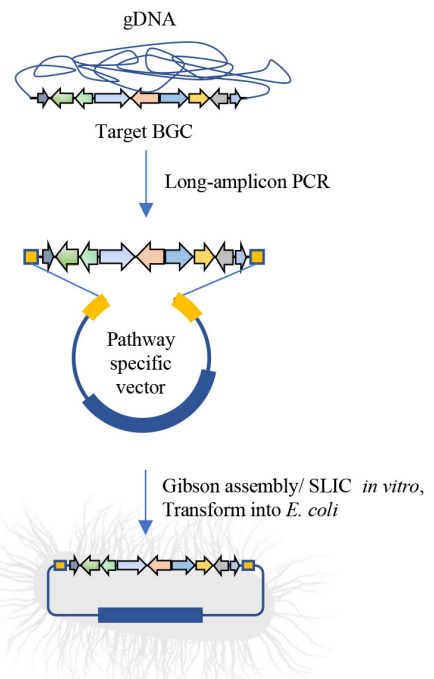

C Restriction enzyme digested/CRISPR-

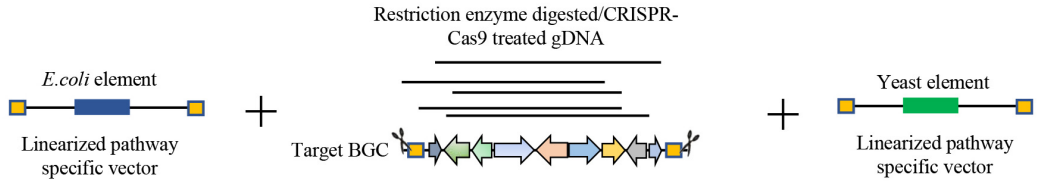
specific vector

Co-transform into yeast
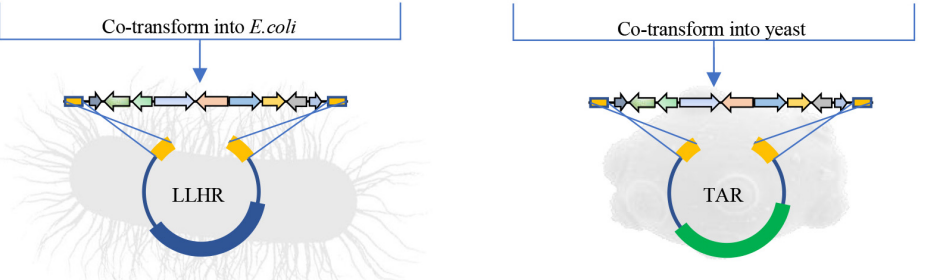

D

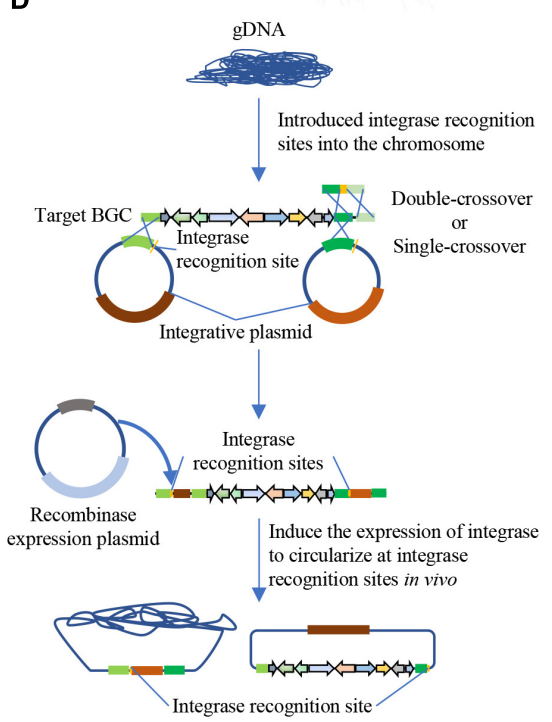

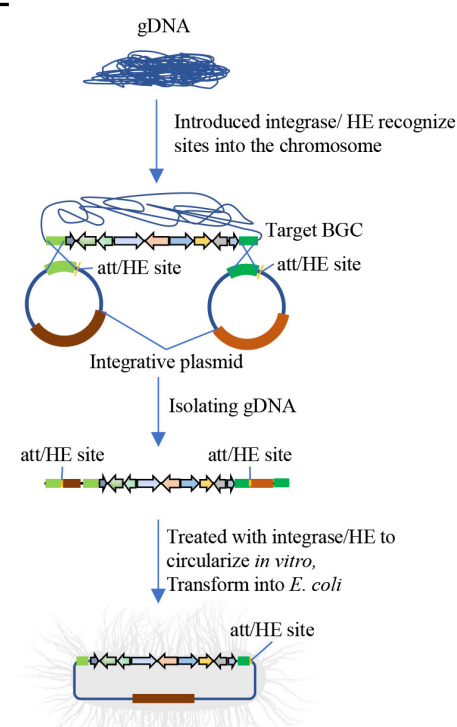

FIGURE 1 | Intact BGC capturing for natural products discovery. (A) Direct cloning method based on enzyme digestion and ligation, including ligation or Gibson assembly-based cloning of BGCs, such as CATCH. (B) Direct cloning method based on long-amplicon PCR and ligation, such as the DiPaC method.

(C) Linear-linear homologous recombination (LLHR) mediated by full RecET in E. coli or transformation-associated recombination (TAR) in yeast for cloning BGCs.

(D) Site-direct recombination for cloning BGC in vivo, including $\phi B T 1$ integrase-mediated in vivo site-specific recombination, Cre/loxP plus BAC. (E) Site-direct recombination for cloning BGC in vitro, including iCatch, $\phi B T 1$ integrase-mediated in vitro recombination. 
recombination (Du et al., 2015), Cre/loxP plus BAC (Hu et al., 2016). These plasmids can then be isolated from the native host for heterologous expression.

As shown in Table 1, compared with in vivo methods (e.g., TAR, LLHR), in vitro cloning methods (e.g., DiPaC, CATCH, iCatch) require carefully preparation of DNA via pre-treatment and purification. Moreover, site-directed recombination methods are suitable for the host with high efficient homologous recombination system. Direct cloning are clearly valuable methods that are well-suited for mining the vast amount of genome for applications in natural product discovery.

\section{Successful Applications}

Over the past decade, direct cloning methods have made great advances and there are already many successful applications (Table 1). For example, Wang et al. (2018) developed a method where exonuclease was combined with ExoCET using the CRISPR/Cas9 cleavage system to digest the target genome and T4 polymerase to pre-anneal linear vector and target DNA before cotransforming into E. coli, resulting in cloning of the $106 \mathrm{~kb}$ salinomycin cluster and a $79 \mathrm{~kb}$ artificial gene cluster (Song et al., 2019). Moreover, TAR has been employed for identification of several novel natural products including orphan cosmomycin (Larson et al., 2017), thiostreptamide S4 (Frattaruolo et al., 2017), and scleric acid (Alberti et al., 2019).

In summary, direct cloning methods can clone intact clusters of interest accurately, and can substantially save time and efforts compared with sequence independent methods. It can also be combined with other modified methods to activated or refactor BGCs in heterologous host. However, current direct cloning methods rely heavily on the quality of genome sequencing and annotation techniques, and have been limited to capture and analyze only one or two clusters each reaction. With the rapidly developed synthetic biology tools available, it will be interesting to see whether these methods can be extended to directly clone all putative BGCs from a give genome in a single reaction.

\section{CONCLUSION AND FUTURE PERSPECTIVES}

In the past decades, the developments in synthetic biology, sequencing technology, and bioinformatics have greatly promoted the discovery of BGCs and corresponding products. We can now easily generate vast genome sequences via nextgeneration sequencing, and annotate them for potential BGCs

\section{REFERENCES}

Alberti, F., Foster, G. D., and Bailey, A. M. (2017). Natural products from filamentous fungi and production by heterologous expression. Appl. Microbiol. Biotechnol. 101, 493-500. doi: 10.1007/s00253-016-8034-2

Alberti, F., Leng, D. J., Wilkening, I., Song, L., Tosin, M., and Corre, C. (2019). Triggering the expression of a silent gene cluster from genetically intractable bacteria results in scleric acid discovery. Chem. Sci. 10, 453-463. doi: 10.1039/ C8SC03814G using defined bioinformatic tools. These predictive BGCs, most of which are putative and do not fall in any known class of BGCs, can be cloned using sequence-independent methods to screen 1000 s of clones in one round, or direct cloning methods to clone and analyze targeted BGCs one by one. However, with current technologies it is still challenging to combine the advantages of both methods, and to use direct cloning methods to test all predictive BGCs from an entire genome in a single reaction. Limitations include that high-quality and high-molecular weight DNAs for generating large BGCs is still difficult to isolate, efficient methods for seperating multi-fragments from digested DNA mixture are still missing, highly effective approaches for library construction of targeted BGCs are still limited. The cloning strategies cited in this review will need to be further optimized for BGCs identification and characterization.

In conclusion, with advancements in synthetic biology along with powerful genome mining techniques, we envision a new era of natural product discovery in which BGC cloning will be highly multiplexable, efficient and accurate in a high-throughput manner, leading to the discovery of numerous novel natural products with important biological activities.

\section{AUTHOR CONTRIBUTIONS}

ZLn, JN, and ZLu drafted the outline and wrote the manuscript. JN and ZLu supervised the research. All authors have read and approved the final manuscript.

\section{FUNDING}

This work was supported by National Key Research and Development Program (2018YFA0903000 and 2018YFA0900100), National Natural Science Foundation of China (21908004), the Novo Nordisk Foundation (NNF10CC1016517), the Knut and Alice Wallenberg Foundation and Beijing Advanced Innovation Center for Soft Matter Science and Engineering.

\section{SUPPLEMENTARY MATERIAL}

The Supplementary Material for this article can be found online at: https://www.frontiersin.org/articles/10.3389/fbioe. 2020.00526/full\#supplementary-material

Baker, K. V., Takano, E., and Breitling, R. (2018). The "Three Cs" of novel antibiotic discovery and production through synthetic biology: biosynthetic gene clusters. Heterologous chassis, and synthetic microbial consortia. Adv. Biosyst. 2, 1-16. doi: 10.1002/adbi.201800064

Bhushan, S., Hossain, H., Lu, Y., Geisler, A., Tchatalbachev, S., Mikulski, Z., et al. (2011). Uropathogenic E. coli induce different immune response in testicular and peritoneal macrophages: implications for testicular immune privilege. PLoS One 6:e28452. doi: 10.1371/journal.pone.002 8452 
Bilyk, O., Sekurova, O. N., Zotchev, S. B., and Luzhetskyy, A. (2016). Cloning and heterologous expression of the grecocycline biosynthetic gene cluster. PLoS One 11:e0158682. doi: 10.1371/journal.pone.0158682

Blin, K., Shaw, S., Steinke, K., Villebro, R., Ziemert, N., Lee, S. Y., et al. (2019). antiSMASH 5.0: updates to the secondary metabolite genome mining pipeline. Nucleic Acids Res. 47, W81-W87. doi: 10.1093/nar/gkz310

Bok, J. W., Ye, R., Clevenger, K. D., Mead, D., Wagner, M., Krerowicz, A., et al. (2015). Fungal artificial chromosomes for mining of the fungal secondary metabolome. BMC Genomics 16:343. doi: 10.1186/s12864-015-1561-x

Cacho, R. A., Tang, Y., and Chooi, Y.-H. (2015). Next-generation sequencing approach for connecting secondary metabolites to biosynthetic gene clusters in fungi. Front. Microbiol. 5:774. doi: 10.3389/fmicb.2014.00774

Clevenger, K. D., Bok, J. W., Ye, R., Miley, G. P., Verdan, M. H., Velk, T., et al. (2017). A scalable platform to identify fungal secondary metabolites and their gene clusters. Nat. Chem. Biol. 13, 895-901. doi: 10.1038/nchembio.2408

Clevenger, K. D., Ye, R., Bok, J. W., Thomas, P. M., Islam, M. N., Miley, G. P., et al. (2018). Interrogation of Benzomalvin biosynthesis using fungal artificial chromosomes with metabolomic scoring (FAC-MS): discovery of a benzodiazepine synthase activity. Biochemistry 57, 3237-3243. doi: 10.1021/acs. biochem. $8 \mathrm{~b} 00076$

Clos, J., and Zander-Dinse, D. (2019). Cosmid library construction and functional cloning. Methods Mol. Biol. 1971, 123-140. doi: 10.1007/978-1-4939-9210-2_6

Cook, T. B., and Pfleger, B. F. (2019). Leveraging synthetic biology for producing bioactive polyketides and non-ribosomal peptides in bacterial heterologous hosts. Medchemcomm 10, 668-681. doi: 10.1039/C9MD00055K

D'Agostino, P. M., Gulder, T. A. M. M., D'Agostino, P. M., and Gulder, T. A. M. M. (2018). Direct pathway cloning combined with sequence- and ligation-independent cloning for fast biosynthetic gene cluster refactoring and heterologous expression. ACS Synth. Biol. 7, 1702-1708. doi: 10.1021/acssynbio. $8 \mathrm{~b} 00151$

Dai, R., Zhang, B., Zhao, G., and Ding, X. (2015). Site-specific recombination for cloning of large DNA fragments in vitro. Eng. Life Sci. 15, 655-659. doi: 10.1002/elsc.201400267

Daniel, R. (2005). The metagenomics of soil. Nat. Rev. Microbiol. 3, 470-478. doi: $10.1038 /$ nrmicro 1160

Dejong, C. A., Chen, G. M., Li, H., Johnston, C. W., Edwards, M. R., Rees, P. N., et al. (2016). Polyketide and nonribosomal peptide retro-biosynthesis and global gene cluster matching. Nat. Chem. Biol. 12, 1007-1014. doi: 10.1038/ nchembio. 2188

Deng, H., Bai, Y., Fan, T., Zheng, X., and Cai, Y. (2020). Advanced strategy for metabolite exploration in filamentous fungi. Crit. Rev. Biotechnol. 40, 180-198. doi: 10.1080/07388551.2019.1709798

Deng, Q., Zhou, L., Luo, M., Deng, Z., and Zhao, C. (2017). Heterologous expression of Avermectins biosynthetic gene cluster by construction of a Bacterial Artificial Chromosome library of the producers. Synth. Syst. Biotechnol. 2, 59-64. doi: 10.1016/j.synbio.2017.03.001

Du, D., Wang, L., Tian, Y., Liu, H., Tan, H., and Niu, G. (2015). Genome engineering and direct cloning of antibiotic gene clusters via phage $\phi B T 1$ integrase-mediated site-specific recombination in Streptomyces. Sci. Rep. 5:8740. doi: 10.1038/srep08740

Duell, E. R., D’Agostino, P. M., Shapiro, N., Woyke, T., Fuchs, T. M., and Gulder, T. A. M. (2019). Direct pathway cloning of the sodorifen biosynthetic gene cluster and recombinant generation of its product in E. coli. Microb. Cell Fact. 18:32. doi: 10.1186/s12934-019-1080-6

Fayed, B., Ashford, D. A., Hashem, A. M., Amin, M. A., El Gazayerly, O. N., Gregory, M. A., et al. (2015). Multiplexed integrating plasmids for engineering of the erythromycin gene cluster for expression in Streptomyces spp. and combinatorial biosynthesis. Appl. Environ. Microbiol. 81, 8402-8413. doi: 10. 1128/AEM.02403-15

Frattaruolo, L., Lacret, R., Cappello, A. R., and Truman, A. W. (2017). A genomicsbased approach identifies a thioviridamide-like compound with selective anticancer activity. ACS Chem. Biol. 12, 2815-2822. doi: 10.1021/acschembio. $7 \mathrm{~b} 00677$

Fu, J., Bian, X., Hu, S., Wang, H., Huang, F., Seibert, P. M., et al. (2012). Full-length RecE enhances linear-linear homologous recombination and facilitates direct cloning for bioprospecting. Nat. Biotechnol. 30, 440-446. doi: 10.1038/nbt.2183

Green, M. R., and Sambrook, J. (2018). Isolation and Quantification of DNA. Cold Spring Harb. Protoc 2018:db.to093336. doi: 10.1101/pdb.top093336
Greunke, C., Duell, E. R., D’Agostino, P. M., Glöckle, A., Lamm, K., and Gulder, T. A. M. (2018). Direct Pathway Cloning (DiPaC) to unlock natural product biosynthetic potential. Metab. Eng. 47, 334-345. doi: 10.1016/j.ymben.2018.03. 010

Hao, T., Xie, Z., Wang, M., Liu, L., Zhang, Y., Wang, W., et al. (2019). An anaerobic bacterium host system for heterologous expression of natural product biosynthetic gene clusters. Nat. Commun. 10:3665. doi: 10.1038/s41467-01911673-0

Harvey, C. J. B., Tang, M., Schlecht, U., Horecka, J., Fischer, C. R., Lin, H.-C., et al. (2018). HEx: a heterologous expression platform for the discovery of fungal natural products. Sci. Adv. 4:eaar5459. doi: 10.1126/sciadv.aar5459

Herisse, M., Ishida, K., Porter, J. L., Howden, B., Hertweck, C., Stinear, T. P., et al. (2019). Identification and mobilization of a cryptic antibiotic biosynthesis gene locus from a human-pathogenic Nocardia isolate. ACS Chem. Biol. [Epub ahead of print].

Hu, S., Liu, Z., Zhang, X., Zhang, G., Xie, Y., Ding, X., et al. (2016). “Cre/loxP plus BAC": a strategy for direct cloning of large DNA fragment and its applications in Photorhabdus luminescens and Agrobacterium tumefaciens. Sci. Rep. 6:29087. doi: $10.1038 /$ srep29087

Hu, Y., Nan, F., Maina, S. W., Guo, J., Wu, S., and Xin, Z. (2018). Clone of plipastatin biosynthetic gene cluster by transformation-associated recombination technique and high efficient expression in model organism Bacillus subtilis. J. Biotechnol. 288, 1-8. doi: 10.1016/j.jbiotec.2018.10.006

Ignatov, K. B., Blagodatskikh, K. A., Shcherbo, D. S., Kramarova, T. V., Monakhova, Y. A., and Kramarov, V. M. (2019). Fragmentation Through Polymerization (FTP): A new method to fragment DNA for next-generation sequencing. PLoS One 14:e0210374. doi: 10.1371/journal.pone.0210374

Jiang, W., Zhao, X., Gabrieli, T., Lou, C., Ebenstein, Y., and Zhu, T. F. (2015). Cas9-Assisted Targeting of CHromosome segments CATCH enables one-step targeted cloning of large gene clusters. Nat. Commun. 6:8101. doi: 10.1038/ ncomms 9101

Kautsar, S. A., Blin, K., Shaw, S., Navarro-Muñoz, J. C., Terlouw, B. R., van der Hooft, J. J. J., et al. (2019). MIBiG 2.0: a repository for biosynthetic gene clusters of known function. Nucleic Acids Res. 48, D454-D458. doi: 10.1093/nar/ gkz882

Kouprina, N., and Larionov, V. (2019). TAR cloning: perspectives for functional genomics, biomedicine, and biotechnology. Mol. Ther. Methods Clin. Dev. 14, 16-26. doi: 10.1016/j.omtm.2019.05.006

Kouprina, N., Noskov, V. N., and Larionov, V. (2020). Selective isolation of large segments from individual microbial genomes and environmental DNA samples using transformation-associated recombination cloning in yeast. Nat. Protoc. 15, 734-749. doi: 10.1038/s41596-019-0280- 1

Larson, C. B., Crüsemann, M., and Moore, B. S. (2017). PCR-independent method of transformation-associated recombination reveals the cosmomycin biosynthetic gene cluster in an ocean streptomycete. J. Nat. Prod. 80, 1200-1204. doi: 10.1021/acs.jnatprod.6b01121

Lee, N. C. O., Larionov, V., and Kouprina, N. (2015). Highly efficient CRISPR/Cas9-mediated TAR cloning of genes and chromosomal loci from complex genomes in yeast. Nucleic Acids Res. 43:e55. doi: 10.1093/nar/ gkv112

Li, L., Jin, M., Sun, C., Wang, X., Xie, S., Zhou, G., et al. (2017). High efficiency hydrodynamic DNA fragmentation in a bubbling system. Sci. Rep. 7:40745. doi: 10.1038/srep40745

Liao, L., Su, S., Zhao, B., Fan, C., Zhang, J., Li, H., et al. (2019). Biosynthetic potential of a novel Antarctic Actinobacterium Marisediminicola antarctica $\mathrm{ZS} 314^{\mathrm{T}}$ revealed by genomic data mining and pigment characterization. Mar. Drugs 17, 1-15. doi: 10.3390/md17070388

Libis, V., Antonovsky, N., Zhang, M., Shang, Z., Montiel, D., Maniko, J., et al. (2019). Uncovering the biosynthetic potential of rare metagenomic DNA using co-occurrence network analysis of targeted sequences. Nat. Commun. 10:3848. doi: 10.1038/s41467-019-11658-z

Liu, C., Liu, X., Lei, L., Guan, H., and Cai, Y. (2016). Fosmid library construction and screening for the maize mutant gene Vestigial glume 1. Crop J. 4, 55-60. doi: 10.1016/j.cj.2015.09.003

Liu, Q., Shen, Q., Bian, X., Chen, H., Fu, J., Wang, H., et al. (2016). Simple and rapid direct cloning and heterologous expression of natural product biosynthetic gene cluster in Bacillus subtilis via Red/ET recombineering. Sci. Rep. 6:34623. doi: $10.1038 /$ srep34623 
Liu, Y., Zhang, B., Wen, X., Zhang, S., Wei, Y., Lu, Q., et al. (2018). Construction and characterization of a bacterial artificial chromosome library for Gossypium mustelinum. PLoS One 13:e0196847. doi: 10.1371/journal.pone.0196847

Luo, C., Chen, Y., Liu, X., Wang, X., Wang, X., Li, X., et al. (2019). Engineered biosynthesis of cyclic lipopeptide locillomycins in surrogate host Bacillus velezensis FZB42 and derivative strains enhance antibacterial activity. Appl. Microbiol. Biotechnol. 103, 4467-4481. doi: 10.1007/s00253-019-09784-1

Luo, Y., Enghiad, B., and Zhao, H. (2016). New tools for reconstruction and heterologous expression of natural product biosynthetic gene clusters. Nat. Prod. Rep. 33, 174-182. doi: 10.1039/c5np00085h

Mayjonade, B., Gouzy, J., Donnadieu, C., Pouilly, N., Marande, W., Callot, C., et al. (2016). Extraction of high-molecular-weight genomic DNA for longread sequencing of single molecules. Biotechniques 61, 203-205. doi: 10.2144/ 000114460

Mo, J., Ye, J., Chen, H., Hou, B., Wu, H., and Zhang, H. (2019). Cloning and identification of the Frigocyclinone biosynthetic gene cluster from Streptomyces griseus strain NTK 97. Biosci. Biotechnol. Biochem. 83, 2082-2089. doi: 10.1080/ 09168451.2019.1638755

Mohamad Roslan, M. A., Naim Mohamad, M. A., and Mohd Omar, S. (2017). High-quality DNA from peat soil for metagenomic studies: a minireview on DNA extraction methods. Sci. Herit. J. 1, 01-06. doi: 10.26480/gws.02.2017.01. 06

Mullis, M. M., Rambo, I. M., Baker, B. J., and Reese, B. K. (2019). Diversity, ecology, and prevalence of antimicrobials in nature. Front. Microbiol. 10:2518. doi: $10.3389 /$ fmicb. 2019.02518

Nara, A., Hashimoto, T., Komatsu, M., Nishiyama, M., Kuzuyama, T., and Ikeda, H. (2017). Characterization of bafilomycin biosynthesis in Kitasatospora setae KM-6054 and comparative analysis of gene clusters in Actinomycetales microorganisms. J. Antibiot. 70, 616-624. doi: 10.1038/ja.2017.33

Navarro-Muñoz, J. C., Selem-Mojica, N., Mullowney, M. W., Kautsar, S. A., Tryon, J. H., Parkinson, E. I., et al. (2019). A computational framework to explore largescale biosynthetic diversity. Nat. Chem. Biol. 16, 60-68. doi: 10.1038/s41589019-0400-9

Nielsen, J. (2019). Cell factory engineering for improved production of natural products. Nat. Prod. Rep. 36, 1233-1236. doi: 10.1039/C9NP00005D

Nielsen, J. C., and Nielsen, J. (2017). Development of fungal cell factories for the production of secondary metabolites: linking genomics and metabolism. Synth. Syst. Biotechnol. 2, 5-12. doi: 10.1016/j.synbio.2017.02.002

Peng, Q., Gao, G., Lü, J., Long, Q., Chen, X., Zhang, F., et al. (2018). Engineered Streptomyces lividans strains for optimal identification and expression of cryptic biosynthetic gene clusters. Front. Microbiol. 9:3042. doi: 10.3389/fmicb.2018. 03042

Pham, J. V., Yilma, M. A., Feliz, A., Majid, M. T., Maffetone, N., Walker, J. R., et al. (2019). A review of the microbial production of bioactive natural products and biologics. Front. Microbiol. 10:1404. doi: 10.3389/fmicb.2019.01404

Qian, Z., Bruhn, T., D’Agostino, P. M., Herrmann, A., Haslbeck, M., Antal, N., et al. (2020). Discovery of the streptoketides by direct cloning and rapid heterologous expression of a cryptic PKS II gene cluster from Streptomyces sp. Tü 6314. J. Org. Chem. 85, 664-673. doi: 10.1021/acs.joc.9b02741

Qiao, Y.-M., Yu, R.-L., and Zhu, P. (2019). Advances in targeting and heterologous expression of genes involved in the synthesis of fungal secondary metabolites. RSC Adv. 9, 35124-35134. doi: 10.1039/C9RA06908A

Robey, M. T., Ye, R., Bok, J. W., Clevenger, K. D., Islam, M. N., Chen, C., et al. (2018). Identification of the first diketomorpholine biosynthetic pathway using FAC-MS technology. ACS Chem. Biol. 13, 1142-1147. doi: 10.1021/acschembio. $8 \mathrm{~b} 00024$

Shi, J., Zeng, Y. J., Zhang, B., Shao, F. L., Chen, Y. C., Xu, X., et al. (2019). Comparative genome mining and heterologous expression of an orphan NRPS gene cluster direct the production of ashimides. Chem. Sci. 10, 3042-3048. doi: 10.1039/C8SC05670F

Skinnider, M. A., Merwin, N. J., Johnston, C. W., and Magarvey, N. A. (2017). PRISM 3: expanded prediction of natural product chemical structures from microbial genomes. Nucleic Acids Res. 45, W49-W54. doi: 10.1093/nar/gkx320

Song, C., Luan, J., Cui, Q., Duan, Q., Li, Z., Gao, Y., et al. (2019). Enhanced heterologous spinosad production from a $79-\mathrm{kb}$ synthetic Multioperon assembly. ACS Synth. Biol. 8, 137-147. doi: 10.1021/acssynbio.8b00402
Tao, W., Chen, L., Zhao, C., Wu, J., Yan, D., Deng, Z., et al. (2019). In vitro packaging mediated one-step targeted cloning of natural product pathway. ACS Synth. Biol. 8, 1991-1997. doi: 10.1021/acssynbio.9b00248

Tietz, J. I., Schwalen, C. J., Patel, P. S., Maxson, T., Blair, P. M., Tai, H.-C., et al. (2017). A new genome-mining tool redefines the lasso peptide biosynthetic landscape. Nat. Chem. Biol. 13, 470-478. doi: 10.1038/nchembio.2319

Tomm, H. A., Ucciferri, L., and Ross, A. C. (2019). Advances in microbial culturing conditions to activate silent biosynthetic gene clusters for novel metabolite production. J. Ind. Microbiol. Biotechnol. 46, 1381-1400. doi: 10.1007/s10295019-02198-y

Tu, J., Li, S., Chen, J., Song, Y., Fu, S., Ju, J., et al. (2018). Characterization and heterologous expression of the neoabyssomicin/abyssomicin biosynthetic gene cluster from Streptomyces koyangensis SCSIO 5802. Microb. Cell Fact. 17:28. doi: 10.1186/s12934-018-0875-1

Wang, H., Li, Z., Jia, R., Yin, J., Li, A., Xia, L., et al. (2018). ExoCET: exonuclease in vitro assembly combined with RecET recombination for highly efficient direct DNA cloning from complex genomes. Nucleic Acids Res. 46:e28. doi: $10.1093 / \mathrm{nar} / \mathrm{gkx} 1249$

Wang, J., Wang, J., Lu, A., Liu, J., Huang, W., Cai, Z., et al. (2019). iCatch: a new strategy for capturing large DNA fragments using homing endonucleases. Acta Biochim. Biophys. Sin. 51, 97-103. doi: 10.1093/abbs/gmy139

Wolpert, M., Heide, L., Kammerer, B., and Gust, B. (2008). Assembly and heterologous expression of the coumermycin al gene cluster and production of new derivatives by genetic engineering. Chembiochem 9, 603-612. doi: 10 . 1002/cbic.200700483

Xiong, Q., Xie, C., Zhang, Z., Liu, L., Powell, J. T., Shen, Q., et al. (2019). DNA origami post-processing by CRISPR-Cas12a. Angew. Chem. 132:201915555. doi: 10.1002/ange.201915555

Xu, W., Klumbys, E., Ang, E. L., and Zhao, H. (2020). Emerging molecular biology tools and strategies for engineering natural product biosynthesis. Metab. Eng. Commun. 10:e00108. doi: 10.1016/j.mec.2019.e00108

Yang, Z., Wei, X., He, J., Sun, C., Ju, J., and Ma, J. (2019). Characterization of the noncanonical regulatory and transporter genes in atratumycin biosynthesis and production in a heterologous host. Mar. Drugs 17:560. doi: 10.3390/ md17100560

Zhang, J. J., Tang, X., and Moore, B. S. (2019). Genetic platforms for heterologous expression of microbial natural products. Nat. Prod. Rep. 36, 1313-1332. doi: 10.1039/C9NP00025A

Zhang, M., Zhang, Y., Scheuring, C. F., Wu, C.-C., Dong, J. J., and Zhang, H.-B. (2012). Preparation of megabase-sized DNA from a variety of organisms using the nuclei method for advanced genomics research. Nat. Protoc. 7, 467-478. doi: 10.1038/nprot.2011.455

Zhang, X., Hindra, and Elliot, M. A. (2019). Unlocking the trove of metabolic treasures: activating silent biosynthetic gene clusters in bacteria and fungi. Curr. Opin. Microbiol. 51, 9-15. doi: 10.1016/j.mib.2019.03.003

Zhang, Y. J., Zhang, S., Liu, X. Z., Wen, H. A., and Wang, M. (2010). A simple method of genomic DNA extraction suitable for analysis of bulk fungal strains. Lett. Appl. Microbiol. 51, 114-118. doi: 10.1111/j.1472-765X.2010.02867.x

Zhao, Q., Wang, L., and Luo, Y. (2019). Recent advances in natural products exploitation in Streptomyces via synthetic biology. Eng. Life Sci. 19, 452-462. doi: 10.1002/elsc.201800137

Zheng, X., Cheng, Q., Yao, F., Wang, X., Kong, L., Cao, B., et al. (2017). Biosynthesis of the pyrrolidine protein synthesis inhibitor anisomycin involves novel gene ensemble and cryptic biosynthetic steps. Proc. Natl. Acad. Sci. U.S.A. 114, 4135-4140. doi: 10.1073/pnas.1701361114

Conflict of Interest: The authors declare that the research was conducted in the absence of any commercial or financial relationships that could be construed as a potential conflict of interest.

Copyright (C) 2020 Lin, Nielsen and Liu. This is an open-access article distributed under the terms of the Creative Commons Attribution License (CC BY). The use, distribution or reproduction in other forums is permitted, provided the original author(s) and the copyright owner(s) are credited and that the original publication in this journal is cited, in accordance with accepted academic practice. No use, distribution or reproduction is permitted which does not comply with these terms. 